\title{
Burns: Treatment and Outcomes
}

\author{
Andrew Burd, M.D., F.R.C.S. ${ }^{1}$
}

ABSTRACT

Burns can cause extensive and devastating injuries of the head and neck. Prevention of the initial injury must always be a priority, but once an injury has occurred, then prevention of progression of the damage together with survival of the patient must be the immediate goals. The acute care will have a major influence on the subsequent scarring, reconstructive need, and long-term outcome. In the majority of cases, the reconstruction will involve restoration of form and function to the soft tissues, and the methods used will depend very much on the extent of scarring locally and elsewhere in the body. In nearly all cases, a significant improvement in functional and aesthetic outcomes can be achieved, which, in conjunction with intensive psychosocial rehabilitation, can lead to high-quality patient outcomes. With the prospect of facial transplantation being a clinical reality, the reconstructive spectrum has opened up even further, and, with appropriate reconstruction and support, no patient should be left economically deprived or socially isolated after a burn injury.

KEYWORDS: Acute care, reconstruction, rehabilitation

A burn is an injury to the tissues caused by a net flux of pathologic energy. This energy may be thermal, chemical, electrical, or radiation. Burns, at one extreme, can be small, superficial, and inconsequential, but at the other extreme they can be devastating injuries that leave a person deformed, disabled, and almost literally imprisoned in scar. This article examines burns of the face and gives an overview of both acute and reconstructive management of head and neck burns. The reconstructive challenges can be daunting, particularly when extensive scarring reduces the options available. Nevertheless, there are considerable personal and professional rewards in using all the available resources, including surgical skills and expertise, splints, therapy, and psychology, to reintegrate a person into society after the long journey that characterizes the recovery of so many burns patients.

\section{PREVENTION}

Undoubtedly, a burn injury is a terrible form of trauma, and prevention must be of paramount importance. Prevention is a function of many factors: the economic development of society, the level of education, and the presence of protective legislation both for the home and the workplace. It is also a function of information. Data, implemented as knowledge, can be used as a tool to persuade and argue for more controls and legislation. It can also be used as power in confronting institutionalized dangers as in industrial practices, electricity distribution, as well as the supply and utilization of petro-chemical products. The data have to reflect the epidemiologic and etiologic nature of the burn: the who, why, where, and when of accidents and incidents. Practices change when accountability and responsibility become issues that cannot be evaded. The prevention of accidents and of the
${ }^{1}$ Division of Plastic, Reconstructive and Aesthetic Surgery, Department of Surgery, The Chinese University of Hong Kong, Prince of Wales Hospital, Hong Kong.

Address for correspondence and reprint requests: Andrew Burd, M.D., F.R.C.S., Professor and Chief, Division of Plastic, Reconstructive and Aesthetic Surgery, Department of Surgery, The Chinese University of Hong Kong, Prince of Wales Hospital, Hong Kong (e-mail: andrewburd@surgery.cuhk.edu.hk).
Advances in Head and Neck Reconstruction, Part II; Guest Editors, Samir Mardini, M.D., Christopher J. Salgado, M.D., and Hung-Chi Chen, M.D., F.A.C.S.

Semin Plast Surg 2010;24:262-280. Copyright (C) 2010 by Thieme Medical Publishers, Inc., 333 Seventh Avenue, New York, NY 10001, USA. Tel: +1(212) 584-4662.

DOI: http://dx.doi.org/10.1055/s-0030-1263068.

ISSN 1535-2188. 
devastating burns after assaults by acid or alkali are global concerns, and campaigns to decrease the problem, active through legislation and passive through education, must be relentless. Criminal attacks associated with thermal or chemical burns must not go unpunished, and the full horror of such assaults must be reflected in appropriate penal sentences.

\section{FIRST AID}

No matter how effective preventive campaigns are, tragically burns will always occur. It is important, therefore, to publicize as much as possible the appropriate first aid for burns. The key basic principles are to remove the source of injury and promote cooling. The application of water can reduce the severity of the burn and thereby lessen complications that otherwise may occur.

\section{Acute Management of the Facial Burn}

Burns of the head and neck are evaluated and managed in the context of the whole patient. The primary survey of airway (plus cervical spine), breathing, circulation, and decompression focuses on the immediate life- and limbsaving procedures that must be considered. ${ }^{1}$ The most important part of this initial evaluation is a critical assessment of the airway. Although a patient may be capable of spontaneous breathing in the early hours after a burn, compromise of the airway can still develop. This may be due to external pressure on the airway, with edema developing in the head and neck region, or in the upper airway due to inhalation of hot gases, including steam or aspiration of hot liquids. Smoke inhalation can cause irritation of the entire respiratory tract. Singed nasal vibrissae or blistering in the oral mucosa should warrant a fiberoptic assessment of the airway. Local practices vary with regard to endotracheal intubation. Where the resources are available, the tendency is to intubate early when it is easy. However, ventilatory support may not be so readily available; in which case, sitting the patient up and under- rather than overresuscitating with intravenous fluids may suffice for borderline cases.

Decompression of the neck or chest may be necessary with deep burns of the head, neck, and trunk. The incisions used to allow respiratory movement should essentially enable the anterior chest to hinge forward. Thus, incisions should be made in the anterior axillary line and across the chest, following the inverted "V" of the costal margin. At the upper end, the incisions can be brought in front of the shoulder and then cross the clavicles at the midclavicular region before extending into the axial neck. The incision should extend down to the muscle fascia, as the main volume of edematous tissue is between the deep and superficial fasciae.

\section{EYES}

Careful examination of the globe should be made during the initial evaluation. The development of edema can fairly rapidly impede appropriate examination. The presence of corneal burns needs to be noted and medicated eye drops administered to promote healing and prevent infection.

\section{EARS}

Burns of the ears are frequently associated with burns of the head and neck region. The major concern is the development of chondritis, which can exacerbate the deformity of ear burns. The application of medicated bandages in the form of ear-muffs not only limits the chance of chondritis but also limits positional deformities of the ears.

\section{Initial Management}

Having secured the airway and addressed concern regarding the eyes and ears, the management of the facial burn has to be considered. Local practices again dictate the options, but factors that need to be considered include:

- Whether the wound needs dressings.

- If dressings are to be applied, what type to choose.

- How often dressings should be changed.

The choice of dressings depends on the available agents. Typically, these will be either biological or synthetic. The choice will be influenced by the depth of burn and the amount of exudate from the wound. The behavior of the wound also dictates the frequency of dressing changes. ${ }^{2}$

The goals of burn wound management include:

- Limitation of pain.

- Prevention of infection.

- Promotion of healing.

- Preparation of wound for surgery, if necessary.

\section{Acute Management of the Burn Wound}

In thermal injuries, the treatment depends on the depth of the burn. ${ }^{3}$

\section{SUPERFICIAL}

In the superficial burn, wound dressings suffice. These can be biological or synthetic. Some medicated element can prevent secondary infection. Superficial facial wounds can also be treated exposed, with or without the application of topical ointments.

\section{PARTIAL THICKNESS}

These burns need to be shaved to preserve residual elements capable of regeneration. Burns of the face rarely 
fall into aesthetic units, and professional judgment must determine how the excision should be performed. Grafting should be in aesthetic units if at all possible, and sheet grafts should be used on the face. The scalp must be considered as a potential donor site because of the excellence of the color match of the grafted skin with the normal facial skin.

\section{FULL THICKNESS}

Full-thickness burns need to be excised. Excision can be done with needle-point diathermy, using a sweeping action on coagulation mode to divide the fine connective tissue fibers around the viable fat lobules in the subcutaneous plane. Occasionally, a fascial excision is necessary. In these full-thickness excisions, thick grafts have to be used to limit resulting contractions. Tissue-engineered products are now available to promote dermal regeneration, but these are extremely expensive. Nevertheless, at this stage much can be done to reduce or prevent development of contractures and complications in the later phases of healing of head and neck burns. The appropriate management of the acute phase of the head and neck burn will significantly reduce the late complications related to scarring and pigmentation (Table 1).

The principle cause of complications after head and neck burns is scarring, which is a consequence of the process of healing by repair. As the process of repair is prolonged, the degree of scarring increases and the severity of complications worsens. One of the key factors responsible for delayed healing is infection. Another, in chemical burns, is residual chemical.

\section{Chemical Burns of the Head and Neck}

Chemical burns are a particularly challenging category of burns, especially those involving the head and neck region. The severity of the burn is a function of the type and concentration of the chemical and the duration of exposure. Burns caused by high concentrations of strong acids or alkalis can result in relatively mild burns. These burns are those likely to happen in well-developed industrial or laboratory settings, where staff is aware of first aid and safety showers. Victims of chemical assault burns are not so lucky, and in many parts of

\section{Table 1 Complications of Head and Neck Burns}

\begin{tabular}{l} 
Functional complications: affect specific features \\
- Eyes \\
- Nose \\
- Mouth \\
- Neck \\
Aesthetic complications: more generalized \\
- Form \\
- Texture \\
- Pigment \\
\hline
\end{tabular}

the world such patients present to the medical services late in the acute stage or even many months later, with the devastating sequelae of dense facial scarring, contractures, blindness, and oral incompetence already established.

Even if the patient does reach medical care within hours of the injury, it remains a considerable challenge to treat the patient and to produce the optimal result. There can be no double-blind randomized controlled trials, and yet, at the same time, there is a desperate need for evidence to support treatment strategies. Our management approach is still evolving, but our best results to date have been based on the following treatment plan.

- Upon admission: continuous water irrigation.

- Urgent: as soon as can be logistically arranged, go to the operating room for a shaving of the involved areas. Shave to punctate bleeding tissue and continue hourly wet soaks for 36 to 48 hours.

- 48 hours: return to the operating room and repeat the shaving to bleeding tissue. If the area is well vascularized, apply sheet or meshed autograft, depending on the extent of the burn. If not well vascularized (e.g., fatty tissue), apply biological dressings and return to the operating room for delayed skin grafting after another 48 hours.

This approach is both labor- and resource-demanding but is justified in view of the terrible aftereffects of chemical burns.

\section{Acute Care: Further Surgical Considerations}

If there have been extensive full-thickness burns of the head and neck region together with smoke inhalation, then very early excision and grafting of the anterior neck should be considered. This approach allows the placement of a tracheostomy through healed skin, permitting easier management of the aesthetic grafting of the facial burns.

The key considerations in the acute phase of management are to thoroughly and repeatedly assess the patient to ensure adequacy of the airway, to protect eye function, to prevent ear deformity, to prevent wound infection, and to promote rapid healing. Skin heals by two basic mechanisms: regeneration and repair. Every attempt should be made to promote regeneration while suppressing repair. This concept, although simply stated, is extremely complex but is a goal that can be partially realized with several therapeutic strategies, which will be considered later.

No matter how aggressive and appropriate the acute care, inevitably some cases can benefit from later reconstruction. As acute care becomes less optimal, this proportion increases, and the third phase of care-reconstruction and rehabilitation-needs to be considered. 


\section{RECONSTRUCTION}

Several predictable facial deformities follow serious burns of the head and neck region; these include:

1. Neck contraction with limitation in range of movement.

2. Contraction of the chin with eversion of the lower lip and problems with oral competence, affecting eating and speech.

3. Microstomia.

4. Flattening and shortening (in vertical height) of the upper lip.

5. Retraction or stenosis of the ala and retraction of the nasal tip.

6. Medial canthal webs.

7. Ectropion of lower and upper eyelids.

In addition, abnormalities of texture and pigmentation may cause concern, as well as focal hypertrophic or keloid scarring not associated with functional problems. ${ }^{4}$

\section{Avoiding Scars}

Although the scar is an inevitable consequence of conventional treatment, the application of tissue engineering has opened up the prospect of avoiding or at least significantly reducing scarring. Integra (Integra Life Sciences, Plainsboro, NJ), for example, is a commercially available product. It is extremely expensive but does enable surgeons to treat full-thickness skin defects in an unprecedented way. Integra is a synthetic product of biological components. It is a bilayer structure composed of a defined matrix of type I bovine collagen and chondroitin sulfate derived from shark cartilage. This matrix is covered with a layer of silicone. The material is placed onto a full-thickness defect and secured with sutures or staples. Macrophages invade the collagenous matrix and begin to biodegrade it. They recruit fibroblasts and endothelial cells, which follow the macrophages into the matrix. The fibroblasts replace the degraded matrix with autologous collagen, and the endothelial cells begin the process of angiogenesis. The pore and fiber sizes of the Integra matrix permit an element of control in the neomatrix formation, and after 3 to 4 weeks the Integra matrix is replaced with a new autocollagenous "dermal" matrix exhibiting organization and morphology that distinguish it from scar tissue. At this stage the silicone is removed, and an ultrathin "epidermal" autograft is placed on the newly formed dermis.

Figure 1 shows the first time that Integra was ever used on a facial burn, this in 1996. This 5-year-old child sustained $85 \%$ body surface area (BSA) full-thickness burns and underwent excision of more than $60 \%$ BSA on day 1 and a further $15 \%$ BSA on day 5 postburn. This $15 \%$ included the face, and Integra was cut and pleated to contour to the face. The Integra was attached in aesthetic units and sutured in place. The patient subsequently died from a pneumococcal septicemia, but lessons learned from this case have been extremely valuable in subsequent cases. Another early case of Integra application to the face involved an 11-monthold girl who was an identical twin. Integra was placed on the left lower eyelid, and a full-thickness postauricular graft was placed on the left upper eyelid. Six-year followup showed very mild medial canthal webbing and slight textural change of the lower lid, but otherwise the patient was very happy with the outcome. ${ }^{5}$

Another early "off-label" application of Integra was in the delayed presentation of a nitric acid burn (Fig. 2). This patient was first seen 5 days postinjury, and there was obvious full-thickness skin loss over the forehead, nose, and cheeks. A full-thickness skin excision was performed and Integra applied. One-year follow-up shows that the shape of the nose remains undistorted, and where the Integra was used there was no hypertrophy. The patient has had no further reconstructive surgery after the acute intervention.

The application of Integra in patients with extensive deep facial burns has been more thoroughly assessed and has been recommended for such burns where other injuries limit thick autograft coverage. It has been suggested that Integra is not good for eyelids because of the
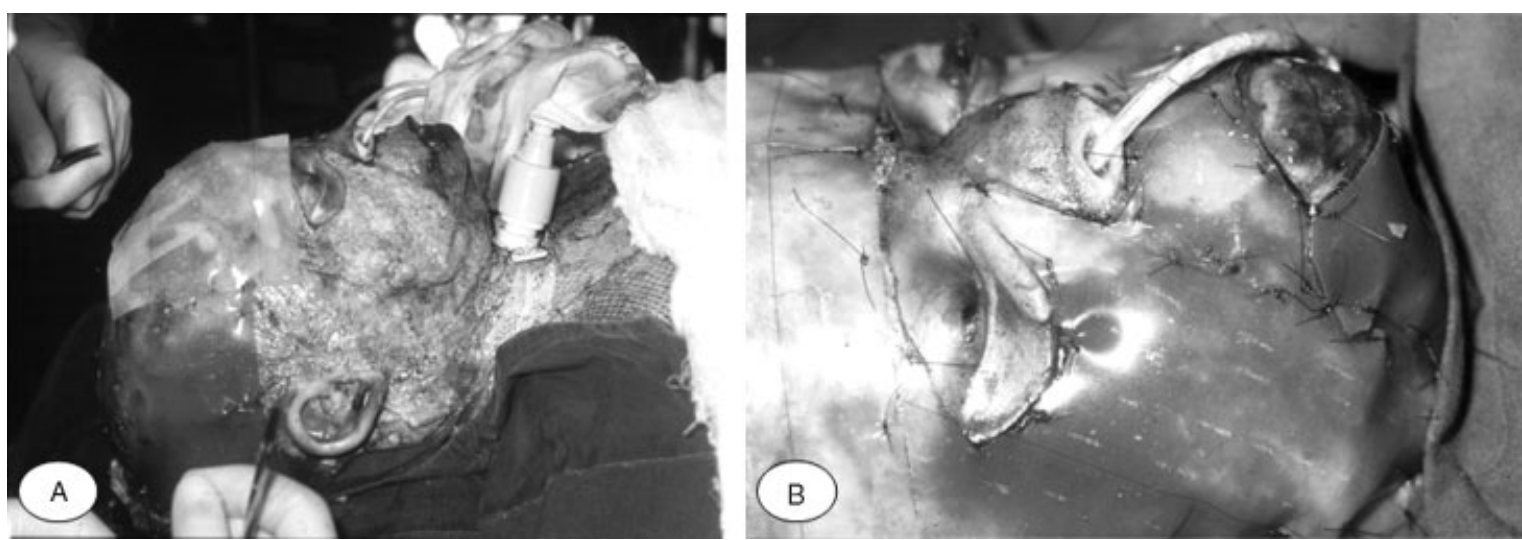

Figure 1 Five days postburn, the full-thickness facial burn was excised and Integra applied in cosmetic units. 

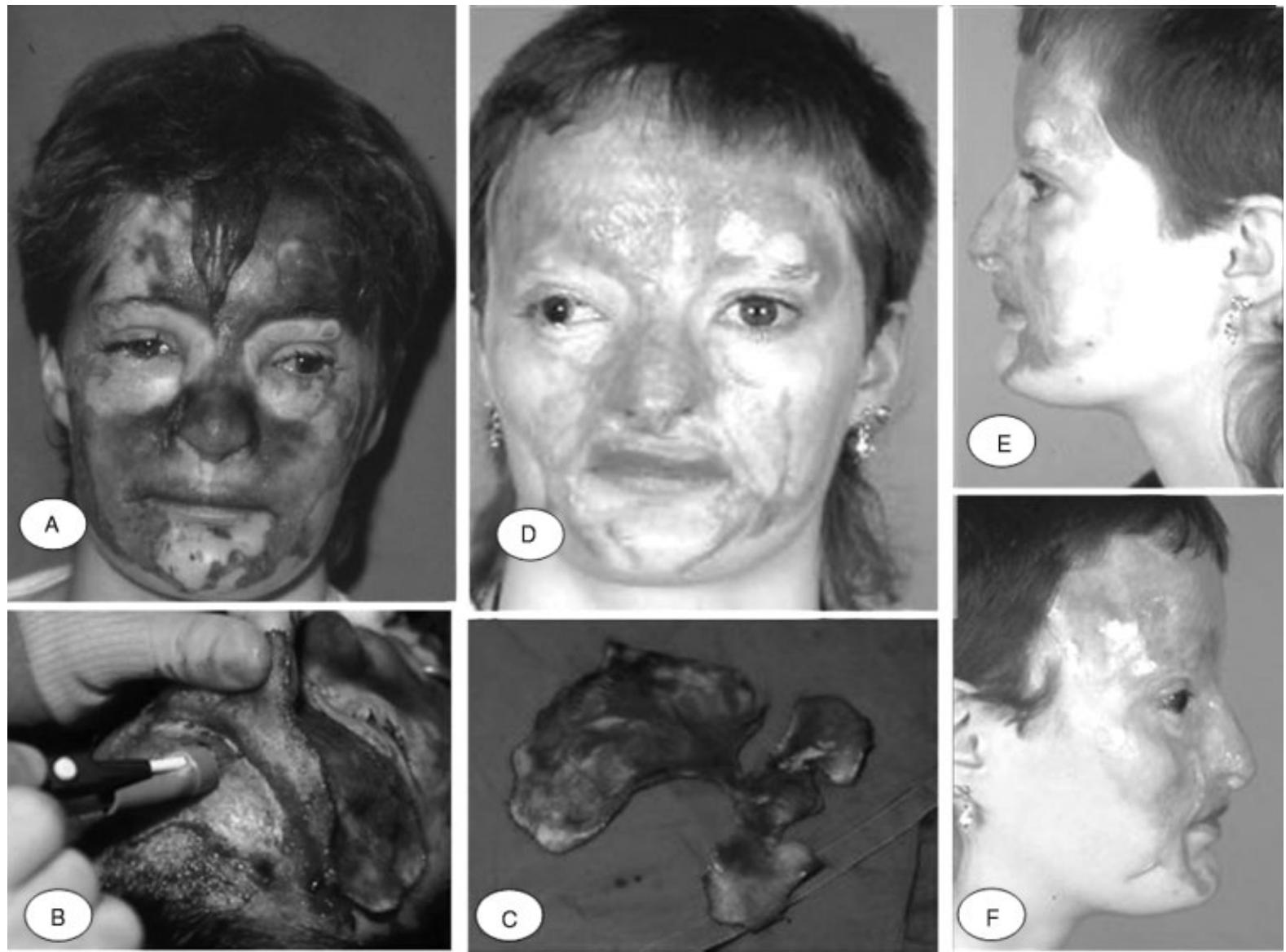

Figure 2 (A) This patient was assaulted with nitric acid and sustained full-thickness burns of the forehead, nose, and cheeks. (B) The burn was excised using needle-point diathermy; (C) the pattern of the excised skin is shown. (D-F) Follow-up photographs at 1 year show that the area reconstructed with Integra is a little red, but otherwise there are no associated contractures or deformity.

delay in vascularization. ${ }^{6}$ For eyelids, there has been some debate about what to use in the acute phase. Although conventional practice has been to use split-thickness grafts in upper lids, ectropion, corneal exposure, and repeated grafting are common sequelae. A review of patients treated in a single center who had either splitor full-thickness grafts of the upper eyelids showed fewer complications in patients treated with the thicker grafts. ${ }^{7}$ As with so many aspects of acute and reconstructive burns, care for each patient has to be considered individually. If there are potential donor sites for full-thickness grafts that would not be needed elsewhere or at a later date, these should be considered in the acute stage for the upper eyelids. When the eyelids are totally destroyed, such debate is no longer applicable. Again, the case has to be considered in the context of available donor sites, and, even in the acute stage, free tissue transfer should be considered. Such situations are reported as cases rather than series, which reflects the uniqueness of each patient. The report by Thai et al described corneal protection with bilateral conjunctival advancement flaps, septal cartilage graft support, and free dorsalis pedis flap cover. ${ }^{8}$ The acute management of the exposed cornea has inspired many ingenious solutions, but in the absence of local tissue, it is inevitable that free flaps have been used, such as the radial forearm flap. ${ }^{9}$

\section{The Scar as the Enemy}

In the reconstructive phase, it is important to be able to understand and predict the behavior of the scarring. Scar tissue is plastic, but the plasticity is very different from that of skin. Scar tissue can be stretched and molded, but the timescale of the remodeling is extremely protracted. For example, Fig. 3 shows a young boy who sustained full-thickness facial burns. As the grafts began to mature, contraction began to cause an ectropion of the right eye. An external splint was made of acrylic. This dynamic splint was worn for 1 year, and the follow-up view shows a complete restoration of anatomy with a full return of function.

\section{Late Sequelae of Burns of the Head and Neck}

Table 2 outlines the late sequelae in terms of complications and their management. The management focuses 

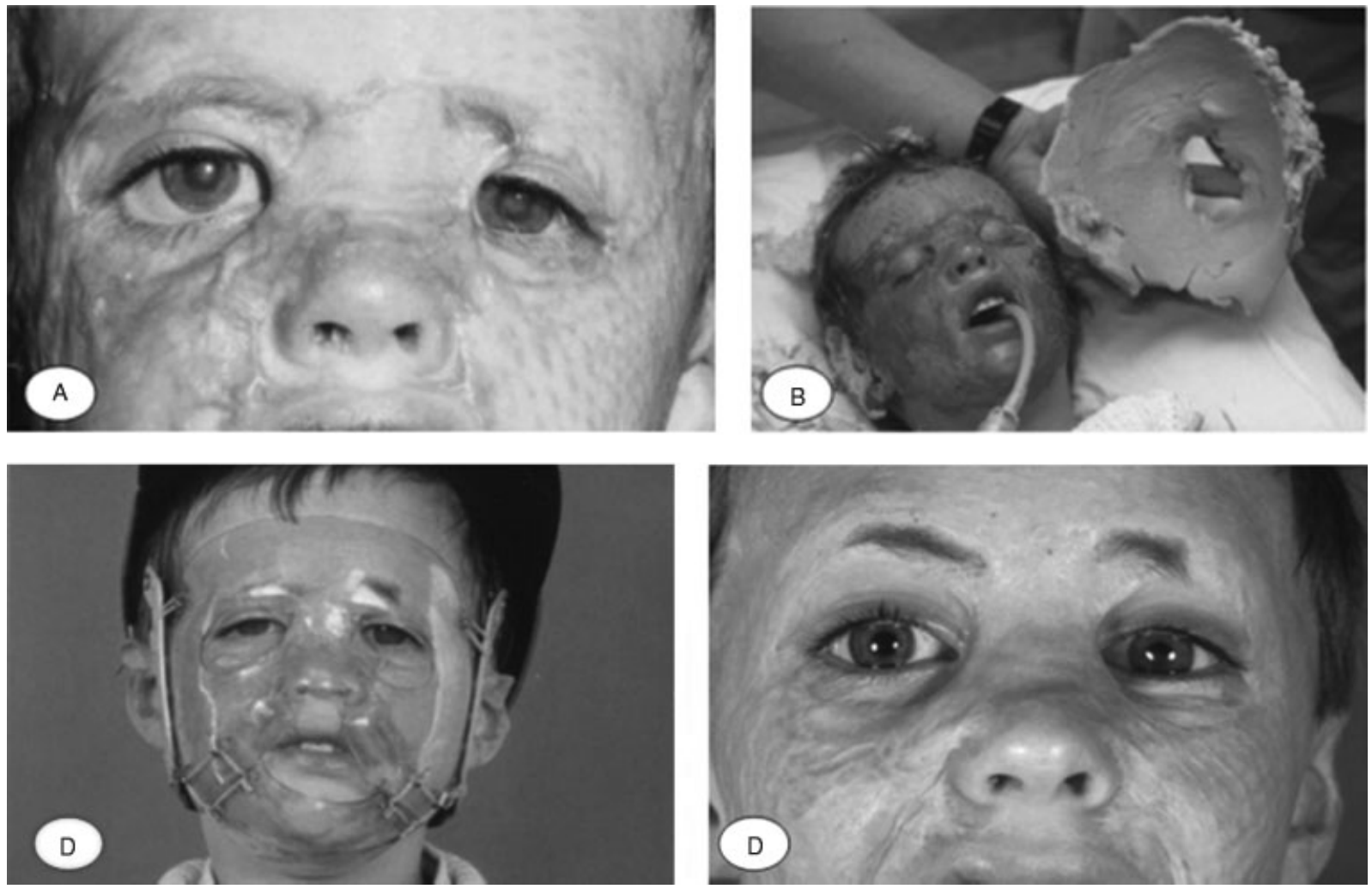

Figure 3 This boy was involved in an explosion in a closed space and sustained deep burns of the hands and face. (A) The eyelids were spared, but contraction of grafts on the cheek was causing distortion of the right lower eyelid. (B) A facial mold was taken under general anesthesia, and (C) a dynamic acrylic splint was made. (D) The mask was worn continuously for more than a year, and the 18-month follow-up view shows complete restoration of anatomy purely from scar molding.

on "skin" and "scar." The difference is a question of degree of abnormality. Some superficial burns will heal with little or no dermal damage and hence no resulting scarring, yet the skin may be red and sensitive to sun, strong soaps, and cosmetics. There may be pigmentary abnormalities. Advice must be given on how to prevent or not exacerbate problems; for example, using sun block, mild topical anti-inflammatory agents (hydrocortisone $1 \%$ cream), or hydroquinones. Moisturizing the skin is important to preventing chafing and cracking, especially around the lips. Such advice is also appropriate when the

\section{Table 2 Management of Late Sequelae}

\begin{tabular}{l} 
Complications \\
- Form \\
- Function \\
- Texture \\
- Pigment \\
Management \\
- Skin care \\
- Scar care \\
○ Nonmedical \\
○ Medical \\
- Nonsurgical \\
○ Surgical \\
\hline
\end{tabular}

burn has been deeper and scar tissue is involved. A range of nonsurgical options is available to reduce the impact of the scar and also to make psychosocial adjustments, so that life with a scar is still meaningful and fulfilling (Table 3).

\section{Surgical Options}

Surgery to deal with complications of facial burns can be extremely challenging. As reconstructive surgeons, we consider an increasing degree of sophistication in techniques in our reconstructive ladder. We are, however, expanding laterally to involve adjunct techniques, which in combination can greatly expand the possible options

Table 3 Nonsurgical Strategies for Dealing with the Late Sequelae of Burns
- Lifestyle
- Topical applications
- Pressure
- Splints
- Silicone
- Laser
- Cell spray
- Psychosocial skills 
Table 4 Surgical Strategies for Dealing with the Late Sequelae of Burns: The Reconstructive Ladder

- Primary closure

- Split-thickness skin graft

- Full-thickness skin graft

- Local flaps

- Distant flaps

- Free flaps

- Tissue expansion

- Tissue engineering

- Biomolecular manipulation

for treatment of the complications (Table 4). The challenge in reconstruction is less concerned with the technical aspects of the surgery and more with the decision-making process. Table 5 reflects the reality that many surgeons face: the compromise between what is possible (i.e., what could be done) and what is practical (i.e., what should be done). This decision is a matter of surgical judgment and has to reflect several factors. The resources available may be plentiful or scarce. New materials, tissue-culture facilities, and operating microscopes may or may not be available. Even if such facilities are available, the expertise to use them to the best advantage may not be available. There may be problems with infection in the cell culture laboratory, or specialized equipment may have been donated or provided without necessary training in its use. In surgical reconstruction, the active involvement of the rehabilitation team is essential to achieve optimum outcome. In the absence of follow-up, there is no guarantee that all has gone well. Single procedures to address only the major problem can be considered. This reality is very different from the textbook ideal of multiple episodes of reconstruction, beginning with the essential functional procedure and ending with the "fine-tuning" procedures. An example of the former would be bilateral commissureplasties to improve the mouth opening; an example of the latter would be reconstruction of the philtrum.

Mention should be made of prosthetics and osseointegration, which can be remarkably realistic. Again, for reconstruction of the head and neck this is a resource-demanding technique. Other techniques that

Table 5 Protocol to Individualize Treatment for Burn Patients

The decision: ?
The "compromise choice": what is possible versus what
is practical
- Resources
- Facilities
- Expertise
- Follow-up
Every patient is different

come under the category of the possible are scalp reconstruction with tissue expanders, laser resurfacing, and pigment reduction. In practical terms, we should recognize that after a severe burn of the head and neck we are dealing with a "renaissance." We need surgery but also, very importantly, psychology. I have mentioned prosthetics, but cosmetics also need to be considered. Aesthetic enhancement can be achieved by waterproof long-lasting cosmetic creams and powders to restore texture and color to scarred skin. Even though cosmetics should not be used on a day-to-day basis, they are an option for special occasions.

\section{Reconstruction of Specific Features}

The following sections deal with reconstruction of specific features of the head and neck.

\section{NASAL RECONSTRUCTION}

The nose is the central feature of the face, around which eyes, ears, and mouth are arranged. As such, it represents a prime aesthetic feature, as well as serving an important functional purpose in breathing. The nose can be reduced in anatomic simplicity to cover and lining, with a structural framework comprising both bone and cartilage. The nose is a feature that has distinct racial differences, which can be described in terms of length, breadth, height, projection, and shape of the nares. The skin of the nose varies from tip to dorsum, being thickly sebaceous at the tip and thin and very pliable over the dorsum. Nasal reconstruction has to take into account all these features, and the essential process involves determining what is lost or missing and what is available to reconstruct or replace. Therefore, the reconstruction of the postburn face can often be considerably more challenging than that of both trauma and postoncologic resection because of the limited availability of local and/ or near-local tissue. As in the reconstruction of other special features of the face, a full spectrum of techniques exists to address the wide spectrum of defects. Skin defects can be replaced with skin grafts, both split and full, as well as tissue-engineered skin substitutes. The challenges begin with contractures of scar, causing deformity of the shape of the nose. A common problem is the retraction of the ale margin, which necessitates replacement of both cover and lining. This can be achieved with a composite graft from the helical rim, if the rim has not been damaged (Fig. 4). Alternatively, the scarred external skin can be advanced to form the new lining and a graft or flap cover can be applied to the outer defect. With loss of more of the structure of the nose, more extensive procedures have to be considered, including the classic forehead flap with or without tissue expansion, ${ }^{10}$ the distant pedicled flap, ${ }^{11}$ and free tissue transfers. ${ }^{12}$ Nasal reconstruction is a complex procedure that may involve multiple stages to transfer tissues, 

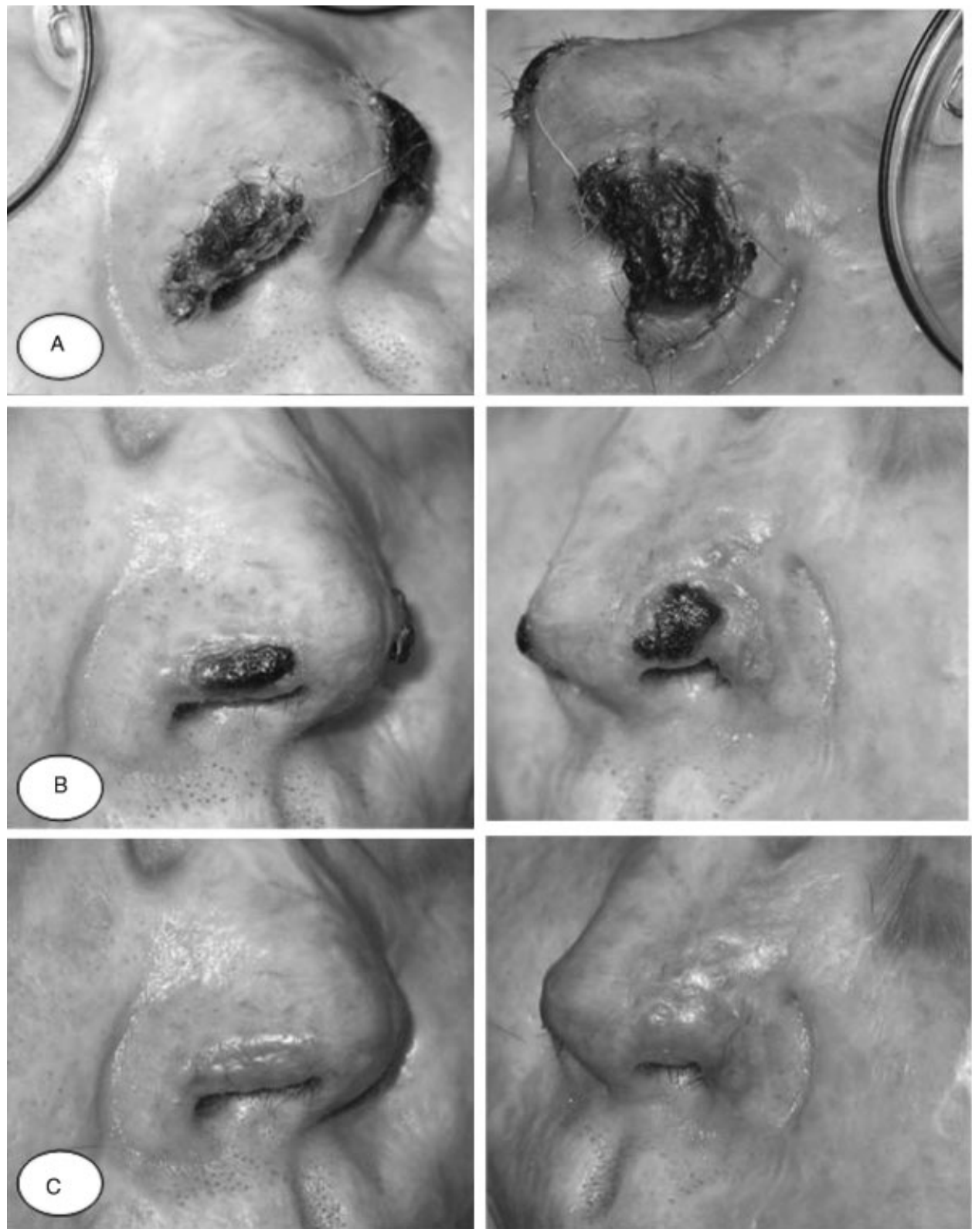

Figure 4 This series of pictures shows the healing of composite grafts applied to both right and left ala margins at 2 week intervals. (A) Two weeks postoperation. This underlines the importance of not rushing in to debride failed grafts. The problem is that the scar bed and composite grafts take longer to revascularize. (B) Four weeks postoperation. (C) After 6 weeks, the alar rims are well formed.

rebuild the support, and refine the shape (Fig. 5). Ultimately, however, it is worth the time and effort to achieve the best possible result because of the central importance of the nose in facial aesthetics. As in other aspects of burn reconstruction, it is essential to listen to the patient and operate only if that is the patient's wish.

\section{THE EAR}

In considering the reconstruction of the ear postburn, the focus is primarily on the external ear as well as the patency of the external auditory meatus. The goal for external ear reconstruction is to restore the function of the helical rim, to provide support for spectacles, and also to present a cosmetically acceptable auricle. The significance of ear deformity will vary with custom and culture, and patients are more generally willing to accept ear deformity than, for example, nose deformity perhaps due to the ability to conceal more readily. The ear represents a complex intrinsic anatomy, but a major contribution of the ear to the aesthetic completeness of the patient is the relative position and orientation of the ear in relation to other facial features. This is particularly evident when facial scarring pulls the ear anteriorly and into a more vertical position (Fig. 6). Another point to establish in analyzing the postburn ear is to determine the nature and the extent of the tissue lost. Unfortunately, in acute burns care, 

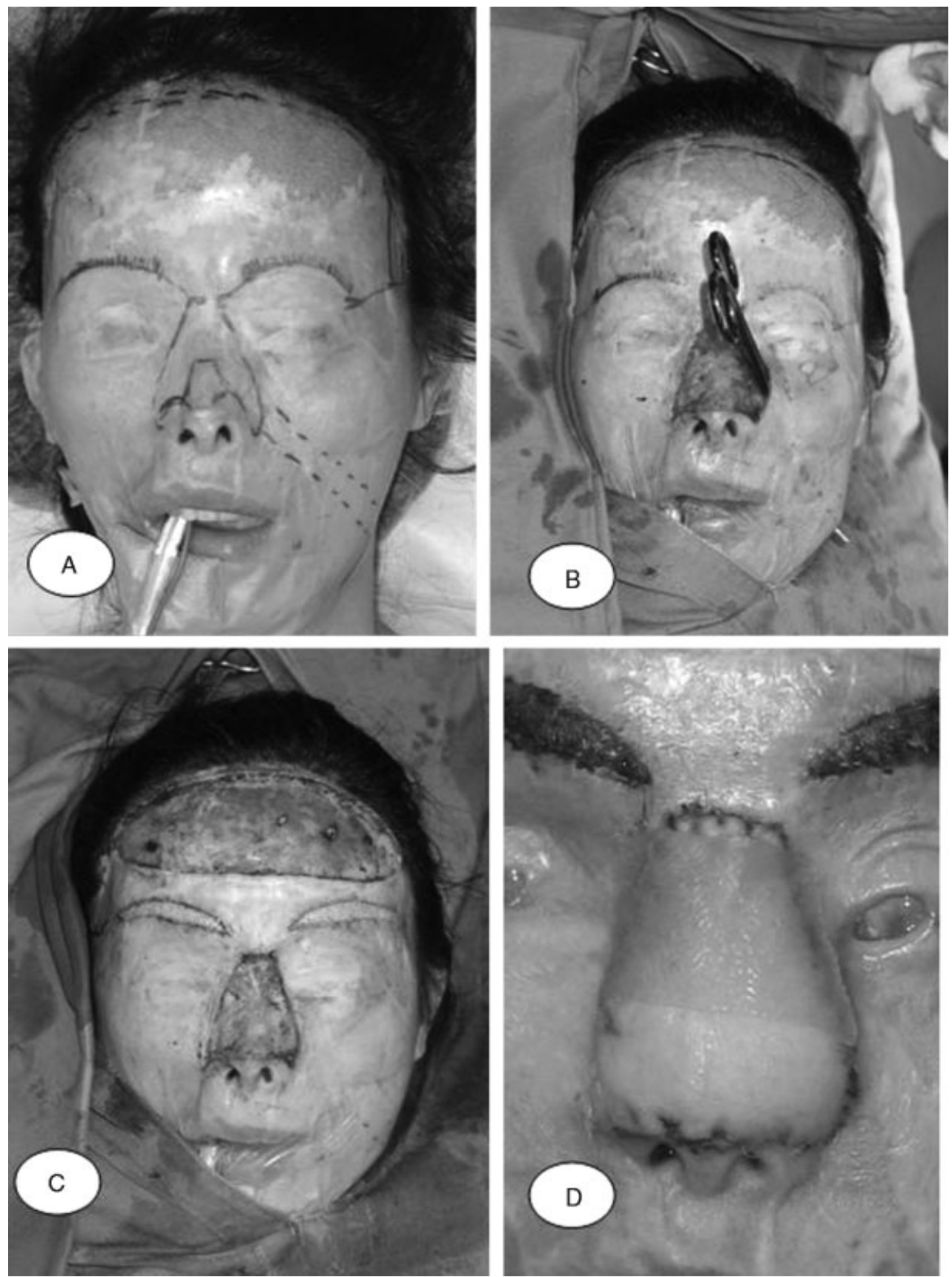

Figure 5 This patient was the victim of an acid assault that left her blind. The scalp was expanded and advanced to cover bare bone on the forehead to provide a graftable bed. (A) New eyebrows are planned, and cover for the nose will be achieved with a free-style perforator flap from the left medial thigh. (B) The distal nasal skin is preserved to act as lining and the scarred dorsal skin excised. A tunnel is made to the left facial artery and vein. (C) The "crane" flap is excised from the forehead and some of the hair-bearing skin used for eyebrows. The defect was closed with a sheet graft and the free flap inset. (D) The patient 2 weeks later with the nasal dorsum covered with a light hydrocolloid gel where she places her glasses. The nose will need to be thinned in stages but already the patient is pleased with the texture compared with the previous scarring. This is an important dimension to consider when operating on blind patients.

protection of the ears is often neglected, and the helical rim can be pulled forward and adhere with scar to the preauricular area. In these situations, restoring the major components of the ear to their original position and using local flaps and applying skin grafts may suffice to give an acceptable appearance. ${ }^{13}$ As the destruction and deform- ity of the ear become more extensive, so the reconstructive challenge becomes greater. The extreme is the total or almost total loss of the external ear, leading to the question of complete reconstruction or replacement. The options of autologous or non-autologous tissues have to be considered. ${ }^{14}$ In simplest terms, the ear is a sandwich 

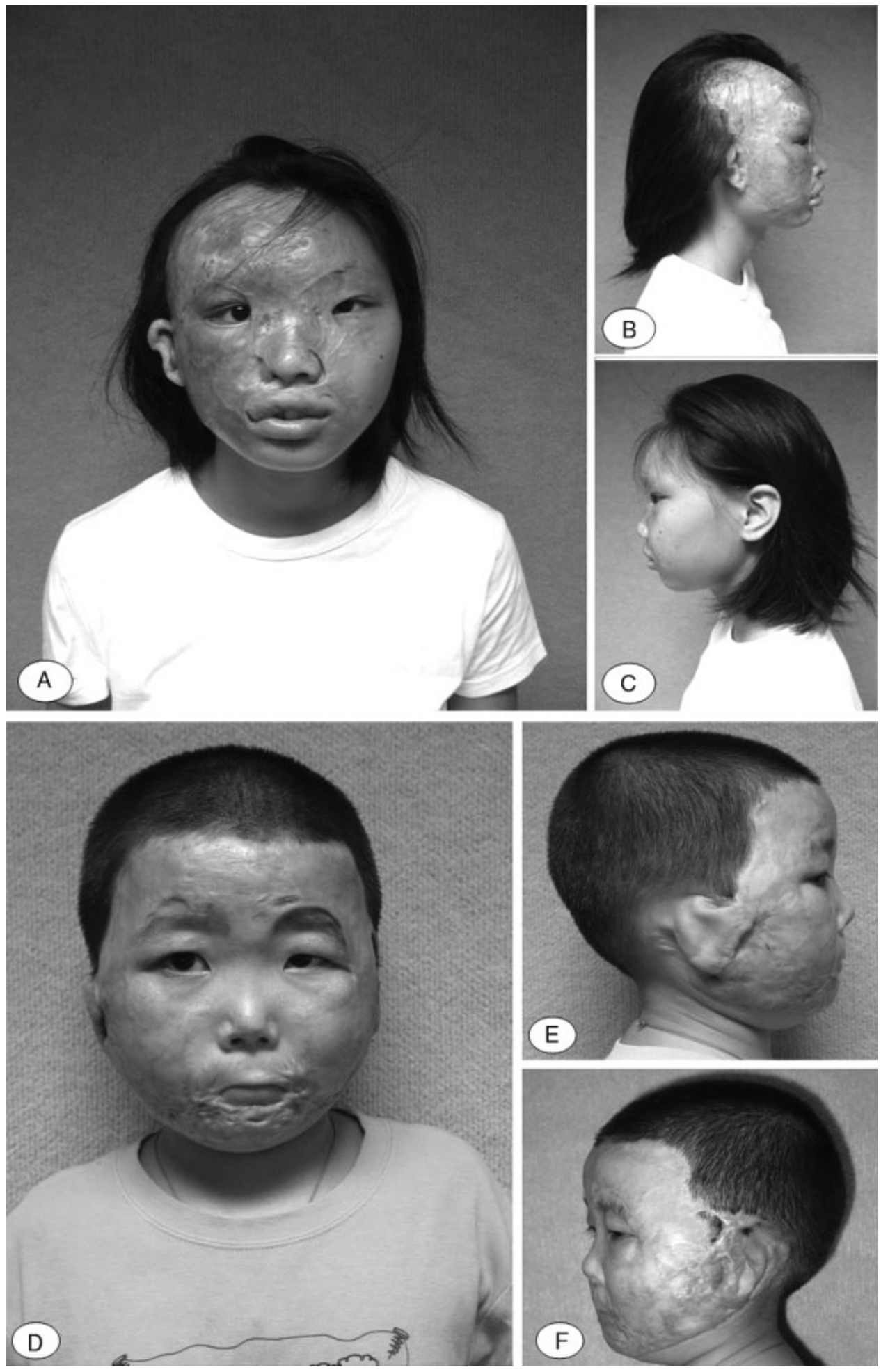

Figure 6 (A) This girl has had severe burns to the right side of the face, and (B) the right ear has been pulled forward by the scarring on the right cheek. (C) This is particularly evident in this patient as the left side is completely unscarred showing the normal orientation and placement of the ear. (D) This young boy has sustained severe facial burns and has a marked microstomia. (E) The right ear has not been badly damaged, but lack of attention in the acute phase has left the helical rim fused to the cheek with scar tissue. Simple release and minor grafting will restore an acceptable ear. (F) The left ear is more significantly burned, but the cartilaginous scaffold is still salvageable. 
of skin, cartilage, and skin. The availability of skin for autologous reconstruction may be a problem in the postburn patient, although it can be imported on a free tissue transfer with a prefabricated ear. ${ }^{15}$ An alternative is temporal fascia covered with graft. Judicious use of skin expansion can create enough for this pliable cover. If local tissue is not available, a variety of free fascia-only flaps are reasonable to use. The skeleton can be constructed from autologous cartilage or foreign materials, such as Medpor (Porex Corporation, Fairborn, GA) porous polyethylene framework. The considerable challenge must be appreciated by both surgeon and patient. In this situation, osseointegration may be feasible.

\section{THE NECK}

The neck comprises a surprisingly large area of skin. The anatomic structure of the neck enables the exten- sive range of flexion, extension, rotation, and lateral tilting on which the normal person relies. The most common postburn problem is a flexion contracture of the neck. A range of surgical procedures can address this problem, encompassing the full extent of the reconstructive ladder. Split-thickness grafts can cover the extensive defects created after scar release. These grafts will need meticulous attention to achieve complete and early wound closure, but thereafter prolonged splintage will be important to maintain release and prevent recontracture. Flaps will be better in maintaining release and reducing the need for further surgery. Flaps may be raised locally with or without prior expansion. Pedicled flaps, particularly the latissimus dorsi myocutaneous flap, can create permanent and effective release. ${ }^{16,17}$ Free flaps again can provide excellent functional and aesthetic results that are long
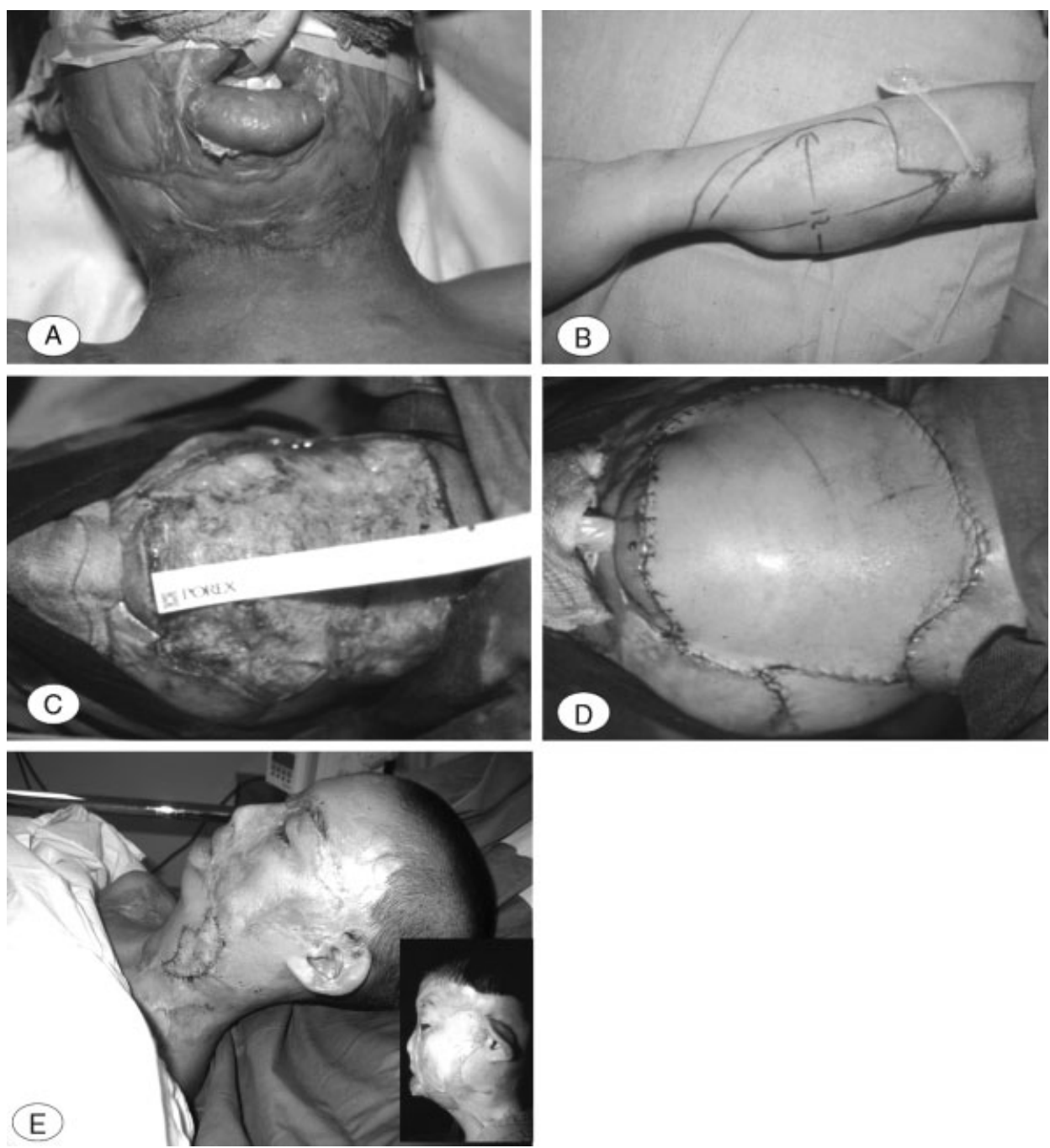

Figure 7 (A) This patient was referred with an extremely foreshortened neck after sustaining facial burns and having the neck skin grafted. (B) A radial forearm flap was expanded using an externalized port on the patient, who had needle phobia. (C) After releasing the neck scar, a $10 \times 12 \mathrm{~cm}$ defect was created (D) that was filled by the flap. (E ) Five years later, the patient presented with some tightening of the left side of the neck associated with the linear flap inset. A free-style perforator flap was raised from the leg and inset with a W-shape to release the scar. The inset shows the original preoperative view, in particular the deformed left ear. 
lasting. ${ }^{18-24}$ Such procedures, however, need to be carefully planned and skillfully executed to achieve optimum results. Thinning of flaps to be used in the neck is a feature allowed by the anterolateral thigh flap, although prior expansion can also create suitably thin flaps when harvested from other sites, including groin and scapula. ${ }^{25-27}$ Thinning alone will not guarantee a good result. One neglected aspect of flap inset is the avoidance of straight lines (Fig. 7), which can give rise to both contractures and webbing but also to pincushioning effects in encircling scars. ${ }^{28}$

If flaps are too thick, recontouring procedures need to be considered. The choice is between an open defatting that is staged or a closed liposuction approach. Both surgeon and patient need to appreciate that one-stage reconstructions of complex functional and aesthetic anatomy can rarely be achieved, and the need for "fine-tuning" and revisionary procedures must be considered.

Another technique in neck reconstruction that has been used to good effect is Integra, the dermal regeneration template. With Integra, as with split-thickness skin grafts, a period of postoperative splintage must be ensured, as contraction is likely to reoccur. ${ }^{29}$ The neck together with the chin in combination should be considered from an aesthetic perspective, particularly with regard to the projection of the chin, which can be corrected with genioplasty, ${ }^{30}$ and the postburn mentosternal angle. ${ }^{31}$

\section{THE FACE}

The human face is a complex blend of textures and contours. The major contributors to the contours are the underlying bony skeleton and the deposition of fatty tissue, while the skin provides the texture. In the majority of burns, particularly thermal burns, most damage is restricted to the cutaneous aspects of the face. The acute care will have a significant influence on the resulting scarring. The extent and nature of the scar will determine the reconstructive need. Hypertrophic scar is associated with contraction, which leads to distortion of the mobile features of the face, in particular the eyelids and the lips. Restoration of anatomic positioning will require removal of the contracting force associated with the scar, by either excision or incision of scar. Either process will create a defect that then needs to be filled. This, then, is the principle of facial reconstruction, which in practice will be influenced by the resources, expertise, and experience of the reconstructive team. From the aesthetic perspective, the face is generally considered in units, and addressing a unit in its entirety is preferable to replacing part of a unit. The aim is to try to restore the face to a wholesome normality, with features that blend into each other, and to avoid an eye-catching patchwork of textures.

Figure 8 portrays the main aesthetic units of the face and also gives an indication of aesthetic proportions, with the face being five eye-widths wide and eight eyewidths high. The eyes are one eye-width apart, and the
A

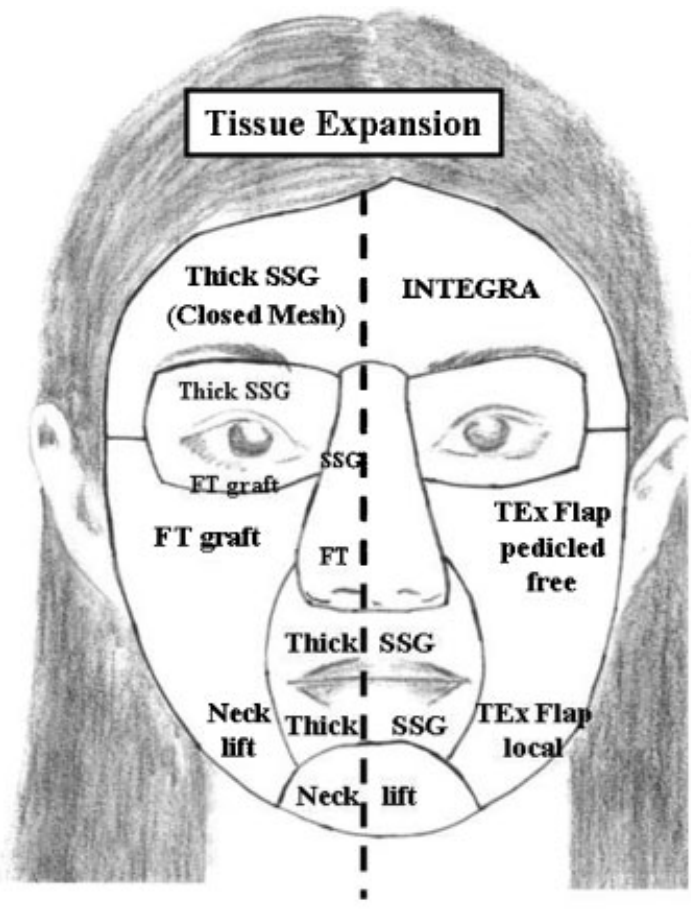

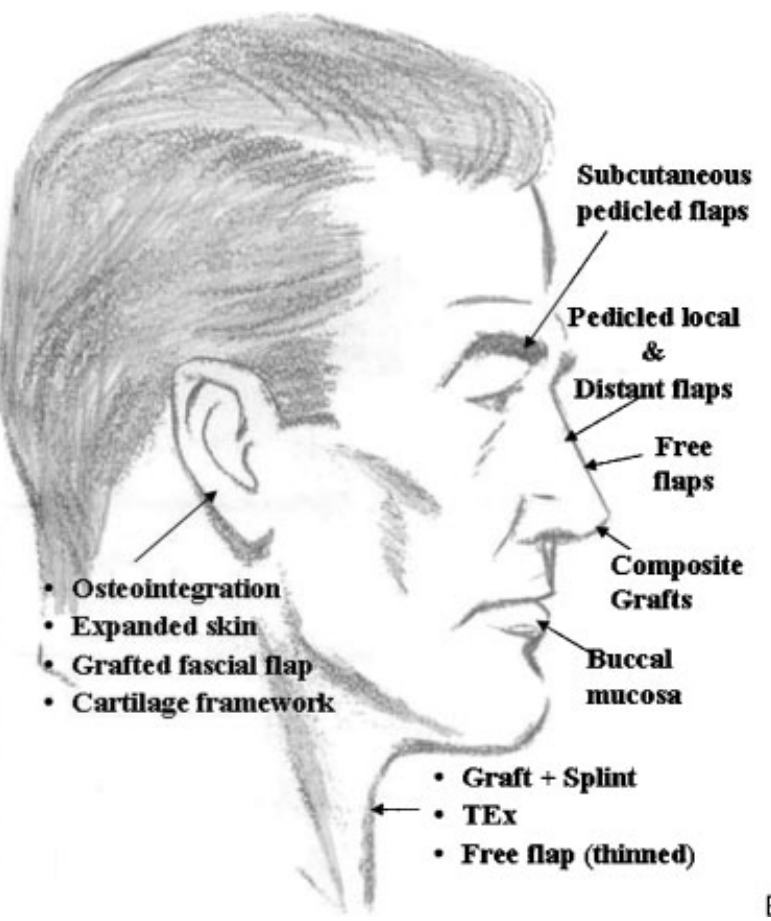

Figure 8 (A) The major aesthetic units of the face are shown together with a variety of strategies for cover. SSG, splitthickness skin graft; FT, full thickness; TEx, tissue expansion. (B) When there is deeper damage, then more complex reconstruction is necessary, especially for the nose and ear. 
A
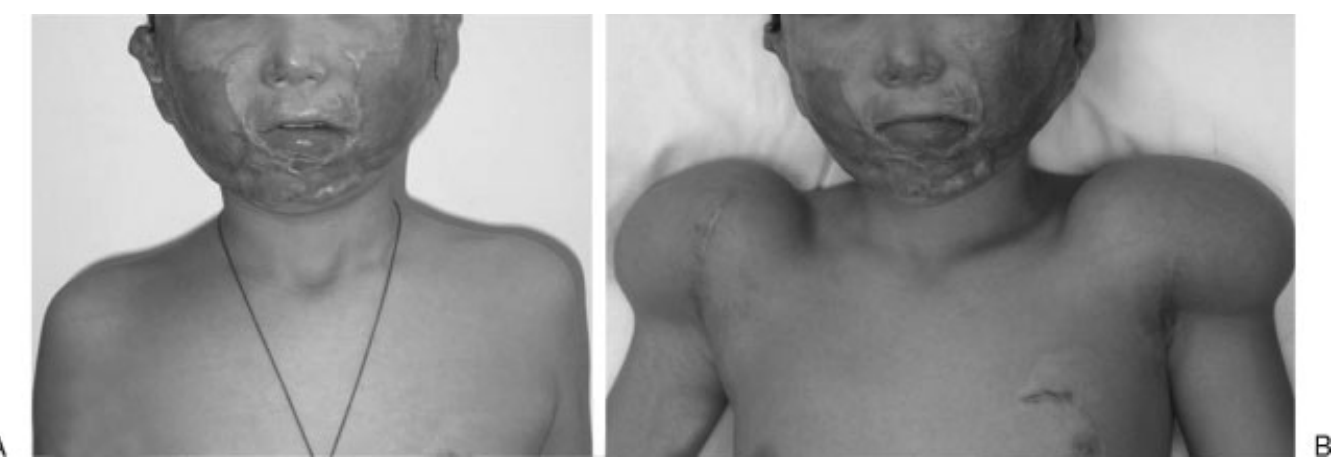

Figure 9 This boy is the same patient who appeared in Fig. 6D-F. (A) The mouth has been opened, a priority when a series of procedures is planned to facilitate anesthesia. The unburned skin in the supraclavicular region makes this an ideal case for creating new full-thickness skin by tissue expansion. (B) Bilateral expanders have been inserted and will be overexpanded to reduce the impact of retraction after positional transfer.

alae nasi span one eye-width. The mouth is wider than the nose, typically in a nose-width to mouth-width ratio of $1: 1.618$. This ratio of 1.618 , known as phi $(\varphi)$, is a basic unit of aesthetic relationship present throughout nature. $^{32}$

The various units can also be regarded differently from the reconstructive perspective; an important consideration is whether the unit is fixed or mobile. In this respect, the forehead can be regarded as a fixed unit, and split-thickness grafts can be used with confidence that there will be little contraction and distortion or deformity of adjacent features. Such grafts, when applied as sheets, can look unnaturally smooth and shining, and the application of a closed mesh may give a duller surface to the skin. The forehead is also a good site for Integra, as it allows a rigid fixation during the stage of biointegration and vascularization and also is not prone to contraction in the remodeling phase.

The chin and cheeks provide another challenge, as they are not only more mobile but also are adjacent to mobile structures (i.e., the eyelids and lips). Reconstruction is often required when there is the need to release contractures and correct deformity. Again, the reconstructive ladder has to be considered, together with the available local and distant tissues. For the cheek, skin grafts, particularly full-thickness ones, can give a very pleasing appearance in terms of texture and movement. Large amounts of skin may be needed, which can be achieved by using prior skin expansion. ${ }^{33}$ However, these grafts can be extremely technically demanding, and the overall success can be marred by a small percentage of graft loss. Limited facial scarring in the lower third of the face can be excised and defects closed by advancement of unburned neck skin. This is not unlike a reverse face-lift procedure, with extensive undermining of neck skin being performed. Such skin can be advanced even higher if there has been prior tissue expansion. Advancing tissue-expanded skin too high, however, is associated with a tendency for the skin to retract, causing scar widening or ectropion. Extreme overexpansion is neces- sary, ${ }^{34}$ and suture suspension of flaps should be considered. ${ }^{35}$ An alternative is to consider pedicled flaps; one particularly useful for replacement of the lower twothirds of the face (Fig. 9) is the expanded supraclavicular artery flap. ${ }^{19,36}$ Pedicled, expanded, and prefabricated flaps, which have received considerable attention in postburn facial reconstruction, have involved several novel techniques, including prefabricated, induced, and expanded flaps ${ }^{37,38}$ as well as prelining flaps. ${ }^{39}$ The range of flaps used is extensive, but attention has to focus on color match and texture, as in the retro-auriculotemporal flap, ${ }^{40}$ as well as adaptability. In the latter respect, the dorsal scapular artery flap can be used as a pedicled flap for facial reconstruction. The flap can be both delayed and expanded to increase its versatility and robustness. ${ }^{41}$

\section{THE SCALP}

Postburn alopecia can be graded according to the extent and density of the hair loss (Table 6). ${ }^{42}$ This classification differs from classifications of scalp burns.

For types I and II alopecia, tissue expansion remains the most effective way to restore an acceptable distribution of hair. Tissue expansion is a technique that has many "tips and tricks" and can be highly rewarding in scalp reconstruction. ${ }^{43,44}$ The appropriate size and shape of the expander must be chosen to allow optimum flap creation. Crescentic expanders can be useful for circular

\section{Table 6 Classification of Burns Alopecia}

\begin{tabular}{ll}
\hline Type I & Single alopecia segment \\
IA & $<25 \%$ of the hair-bearing scalp \\
IB & 25 to $50 \%$ of the hair-bearing scalp \\
IC & 50 to $75 \%$ of the hair-bearing scalp \\
ID & $>75 \%$ of the hair-bearing scalp \\
Type II & Multiple alopecia segments amenable to tissue \\
Type III & expansion placement \\
Type IV & Patchy burn alopecia not amenable to tissue \\
\hline
\end{tabular}


defects, but for linear defects rectangular or cylindrical expanders are better and certainly preferable to circular expanders (Fig. 10). Antibiotics should be used prophylactically at the time of expander insertion, and the elevated pocket should be copiously irrigated with a dilute antimicrobial solution prior to inserting the expander. It is important to ensure that the pocket is large enough to accommodate the expander, particularly when the expander is in the deflated state in which the bone dimension is greater than in the expanded state. Incisions for inserting expanders should ideally be made through normal skin. If they are made radial to the main axis of expansion, the process of expansion can begin early, without a major concern about dehiscence. However, the flap that is going to be created and advanced must be considered; it may be necessary to make an incision parallel to the long axis of the alopecia. Shaving the hair in the region of the incision will decrease the possibility of introducing hair into the expander pocket. Prior to inserting the expander, the pocket should be inspected for bleeding points, as it is preferable to avoid insertion drains, which can theoretically cause trauma to the expander envelope when they are removed. The injection portal can be buried or left externalized. With appropriate care and attention, risk of infection does not appear to be increased with an externalized port. The expander pocket should be closed in layers, with particular attention being paid to avoid accidental puncture of the envelope. Once the wound is closed, the expander can be filled enough to tamponade any oozing within the expander cavity. This technique also allows the envelope to be "unfurled," thus avoiding rolled edges or ridges.

Definitive expansion can begin when the wound used to insert the expander is stable enough not to dehisce during the expansion process. This will depend upon the association of the wound to the expansion forces.

The use of the endoscope certainly allows pockets to be created with smaller incisions, which can help reduce the interval between insertion and definitive expansion. The rate of expansion will be determined by the response of the skin and the patient. Generally, the process begins slowly, but thereafter regular weekly
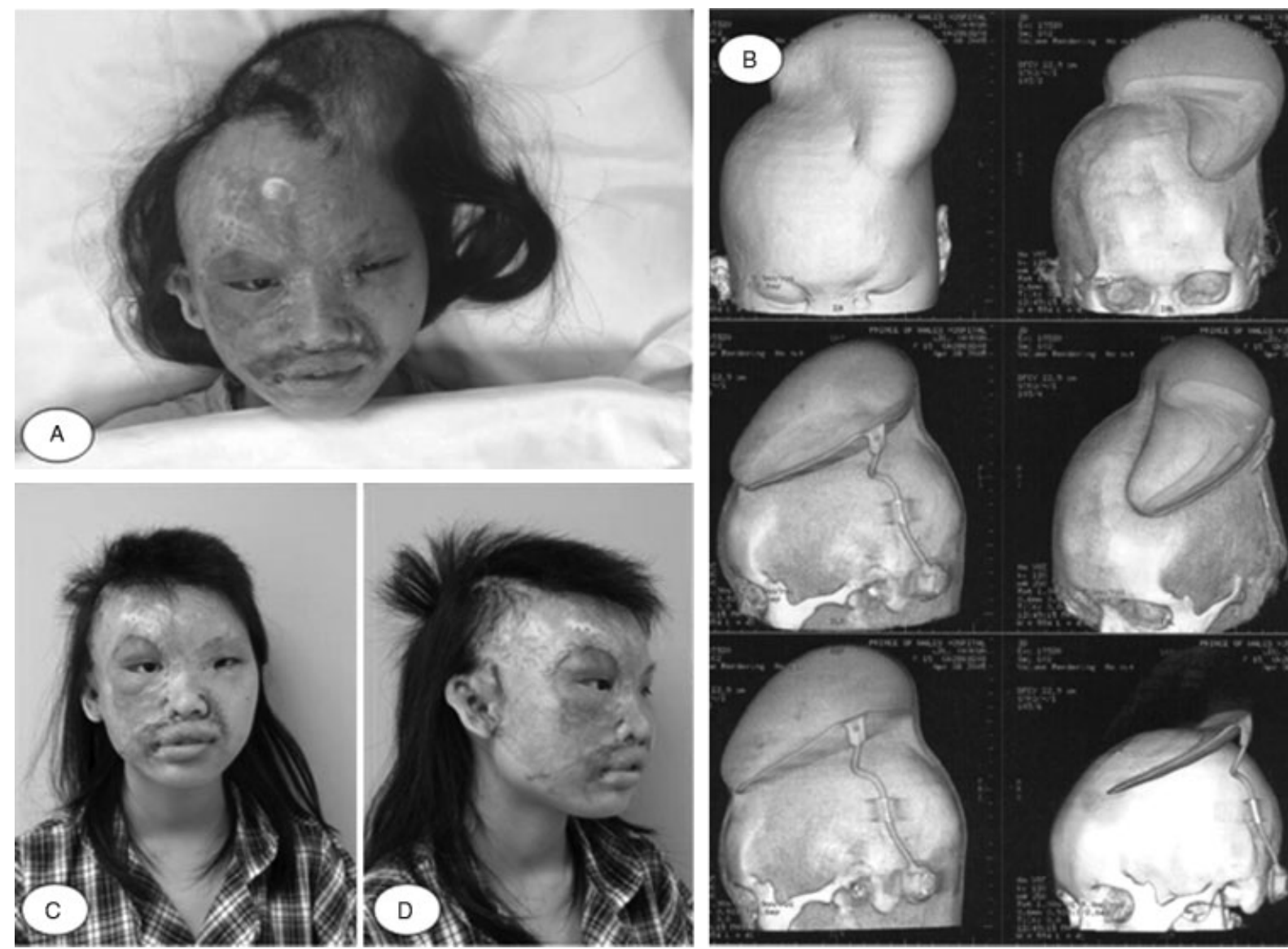

Figure 10 This girl is the same patient who appeared in Fig. 6A-C. (A) A crescentic expander has been chosen. (B) The threedimensional computed tomography scan shows that there is no bone deformity in this 15-year-old girl although this can be a feature in younger children. Because the treatment of this patient has to be staged, she will require a second episode of expansion to extend the hair-bearing scalp into the right temporal region. (C) The postoperative view shows the restoration of the anterior hairline in the midline and also (D) the effect of a small postauricular flap transposition anteriorly that has given the ear a more normal appearance even though the ear itself was not touched. 
expansion can achieve significant incremental volumes to be inserted. As in all flap surgery, the size of flap needed should ideally be larger than the defect to allow for adjustments and inset. A period of rest should be allowed between the final expansion and the removal of the expander and transposition of the flap. This allows the expanded skin to achieve some stability so that it does not immediately shrink after the expander is removed. When insetting the flap, it is important to remember to avoid straight-line scars in hair-bearing skin. The judicious incorporation of $\mathrm{Z}$-plasties will allow the narrow linear bands of alopecia to be suitably camouflaged.

For types III and IV alopecia, the choice for the patient is to wear a wig or, if male, to go with the bald look. This latter approach is quite acceptable for older patients but is a concern for children.

\section{EYELIDS AND EYEBROWS}

The eyelids have an extremely important functional role in protecting the cornea. At the same time, the eyelids have to move to allow for vision. The anatomic complexity of both upper and lower lids cannot be underestimated, and the challenges presented by eyelid reconstruction are formidable, particularly in the postburn patient. The most devastating burns to affect both eyes and eyelids are chemical burns. The depth and extent of destruction associated with these burns would only occur in otherwise lethal thermal injuries. The acute management of burns that affect the eyes and eyelids has to focus on preservation of the cornea at all costs. Thus, if eyelids are damaged or lost, the corneas may be covered with conjunctival flaps, which can then be covered with skin grafts. The use of autologous transplantation of nasal mucosa to reconstruct the fornices is associated with persistence of goblet cells, excess mucus, and protection of the globe. ${ }^{45}$ Reconstruction of the tarsus has been successfully achieved with acellular human dermal allografts, ${ }^{46}$ and more recently lower eyelids have been reconstructed with composite auricular grafts to maintain the shape of the globe and thereby reduce the incidence of opacification. ${ }^{47}$ Subsequent management of such devastating injury may involve the use of scleral lenses with a limited aperture. Dealing with such injuries is a very specialized branch of oculoplastic surgery and is beyond the scope of this article.

The more common deformities of the eyelids involve scar contraction resulting in ectropion of upper and/or lower lids or deformities of medial or lateral canthi. ${ }^{48}$ The surgical management of ectropion involves an analysis of the deficiencies of the tissues and the
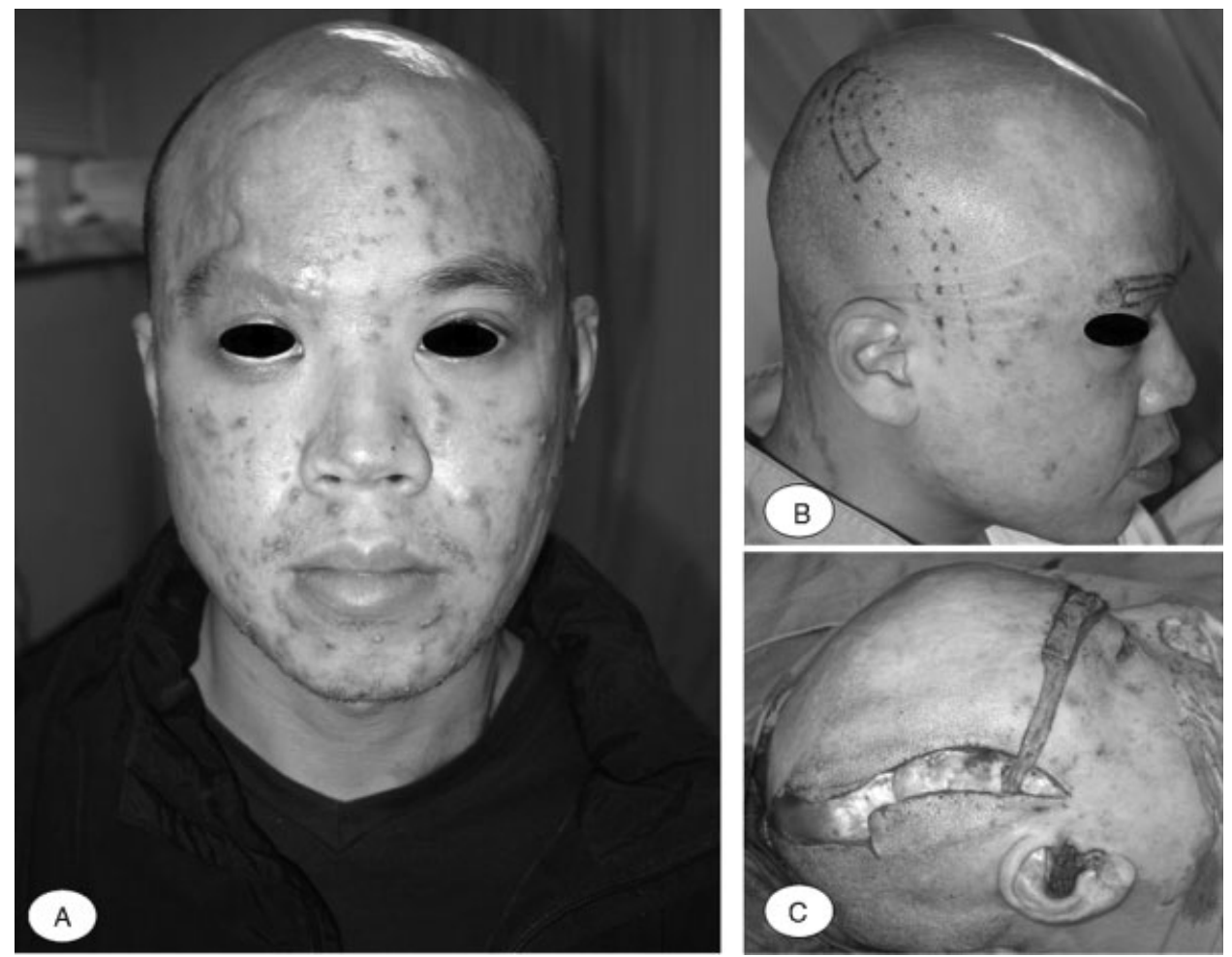

Figure 11 (A) This patient was the victim of an acid assault but was taken immediately to the operating room for debridement. The benefits of this treatment are reflected in the reduced deformity of the deeper structures, particularly on the nose. The eyebrows and scalp were not showed immediately, and although the patient does not mind the patchy alopecia, which he disguises by shaving his head, he believes that loss of the major portion of the right eyebrow is a significant problem. (B) The course of the posterior branch of the superficial temporal artery has been identified using the hand-held Doppler giving an island of hair-bearing scalp. (C) This has been elevated and can be transposed via a subcutaneous tunnel. 
distortion of the anatomy. Lower lid ectropion is often associated with distortion of the tarsal plate, which becomes more horizontal in orientation. Although the scar contracture can be released and indeed overcorrected with skin grafts, the tarsal plate will continue to be misshapen due to elongation. Full or very thick splitthickness grafts are used for the contracture release. The tarsal plate will need to be shortened and refixed with a lateral canthopexy to reposition the tarsal plate in a more vertical orientation. In the upper lid, ectropion is again corrected by scar incision and graft placement, but splitthickness grafts are more commonly used. In both upper and lower lid ectropion, it is important to extend the releasing incisions beyond the respective canthi so that the lid can be suitably released and the grafts fixed with the overdressings.
Medial and lateral canthal webs can be corrected with multiple Z-plasties, local transposition flaps, or both. As these folds rarely cause a significant functional problem, it is better to wait for scar maturation before considering correction.

Eyebrow reconstruction can play an important role in the restoration of aesthetic balance in the postburn face. Several options are available involving free and vascularized procedures. The use of free micrografts, minigrafts, and strip grafts is not always successful, in part because of the hostile scar bed. The best way to achieve a richly dense eyebrow is to use a pedicled vascular graft of scalp hair with a subcutaneous tunnel of a pedicle containing branches of the superficial temporal artery (Fig. 11). Use of this technique can be limited by the distribution of alopecia if there are associated scalp burns.
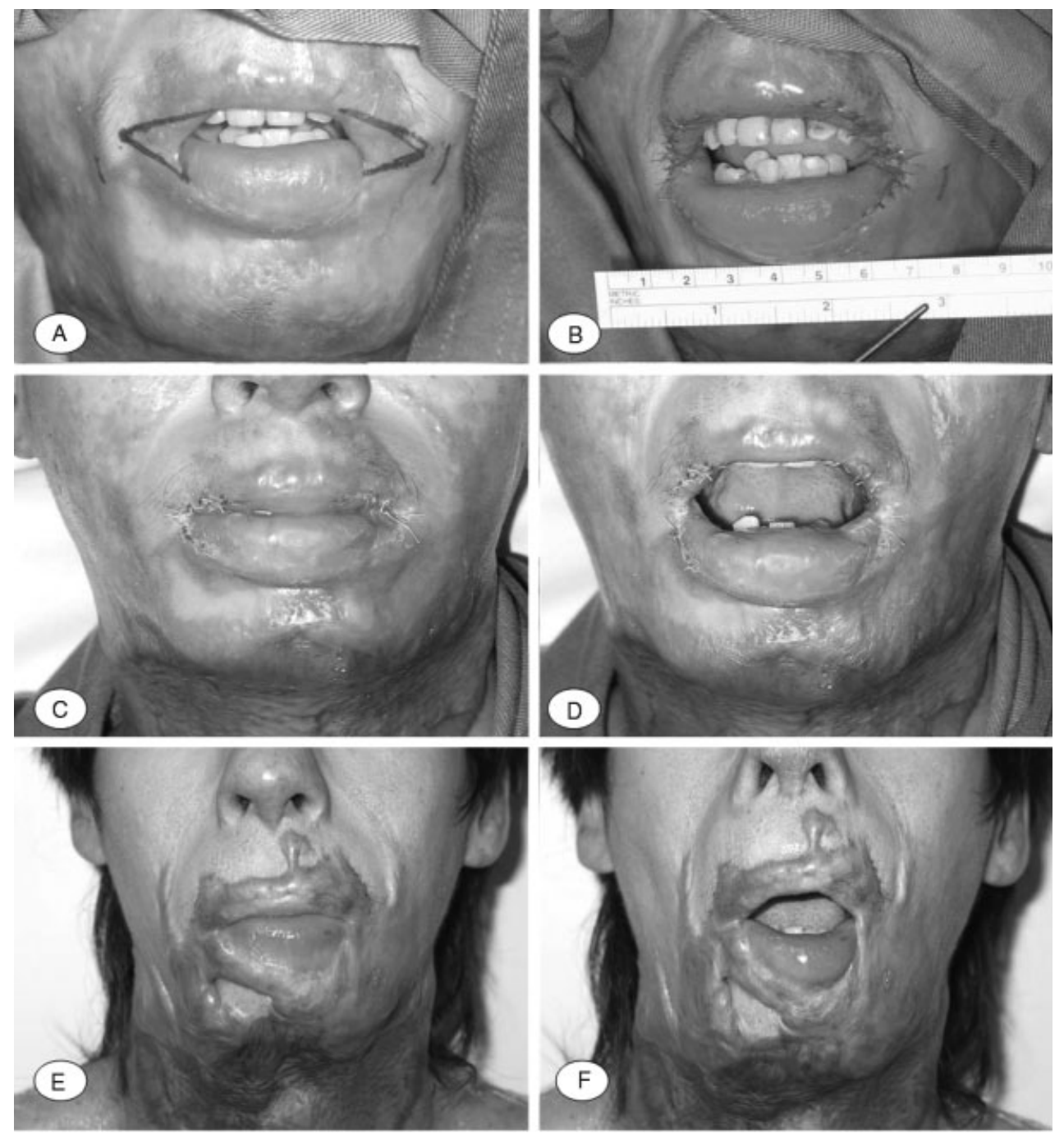

Figure 12 This series illustrates the unforgiving nature of burn scars. (A) A patient developed significant scar contraction in the early postburn phase and (B) a release achieved by bilateral commissureplasties, which gave both (C) an acceptable aesthetic result and (D) a functional result. The patient was provided with a splint and supervised on application and use. Eighteen months later, the patient presented with a significant recurrence of microstomia and no splint. (E, F) A re-release was performed to facilitate anesthesia, and bilateral neck tissue expanders were inserted to allow the scar to be excised and replaced. 


\section{LIPS AND MOUTH}

The lips and the mouth are functionally important in achieving oral continence while eating and drinking and also in the production of intelligible speech. Aesthetically, the size and shape of the mouth, particularly when there is gross eversion of the lips, revealing the teeth, can be of major psychological concern to the patient. The two major deformities encountered are the small, contracted mouth and the large mouth with everted lips and associated scar contractures. The management of microsomia involves oral commissure reconstruction. This will involve recruiting buccal mucosa to effect a new lining of soft tissue after bilateral incisions are made to extend the commissures laterally. In addition, the buccal mucosa is used in vermillion reconstruction.

An excellent practical guide to oral commissure reconstruction appears in Achauer's classic text. ${ }^{49} \mathrm{Mi}^{-}$ crosomia can be associated with oral cavity contractures, particularly in children. These cases are very difficult to treat, but scar release, skin grafting, and prolonged splinting (Fig. 12) are the most common strategies employed. ${ }^{50}$ If the area of scarring is localized, then excision and free tissue transfer can be considered. For the shortened and everted lip, the general management is as for the ectropion of the eyelids. The scar has to be incised and the position of the lip overcorrected, while a suitable thick split-thickness graft is inset and a tie-over dressing applied. There are, of course, several variations on this theme. Local flaps from the nasolabial area can be used if available, in conjunction with other pedicled flaps. ${ }^{51,52}$ Expanded flaps can be brought up to fill defects created by scar excision. This is particularly advantageous in children: The incorporation of full-thickness skin together with this layer of adipose tissue will allow for growth and development and reduce the need for further surgery. Another situation when a flap can be effective is in the male patient with badly scarred or deficient lips. Hairbearing flaps can be used to create either a new upper lip together with mustache, as in the visor flap ${ }^{53}$ or in the hair-bearing submental flap, which can create a beard. ${ }^{54}$ As with other aspects of facial reconstruction, a major part of the challenge is to find and choose the most suitable donor sites and tissue transfer techniques if there is extensive scarring elsewhere in the body. To this end, such clinical techniques as using tube-pedicled flaps may occasionally be useful in such reconstruction. The surgeon involved with aesthetic and functional reconstruction of the postburn patient must be extremely versatile and proficient in an extensive range of reconstructive techniques, both old and new.

\section{Total Reconstruction}

Accounts have been published of very extensive reconstructive procedures to address facial burns; indeed, it is in the context of postburn scarring that face transplantation has been discussed. In 1983, Conley and Norris described reconstruction of the hemi-face with a large deltopectoral flap that was subsequently fine-tuned with several secondary procedures. ${ }^{55}$ In 1995 , Evans described a total facial reconstruction with bilateral circumferential radial forearm flaps and a free dorsalis pedis flap for the nasal tip. A Tagliacozzi flap was used for dorsal nose reconstruction. ${ }^{12}$ In 1999, Angrigiani and Grilli described total face reconstruction using bilateral extended scapular free flaps in five patients for total facial resurfacing, with the exception of the nose, which was treated separately. ${ }^{56}$
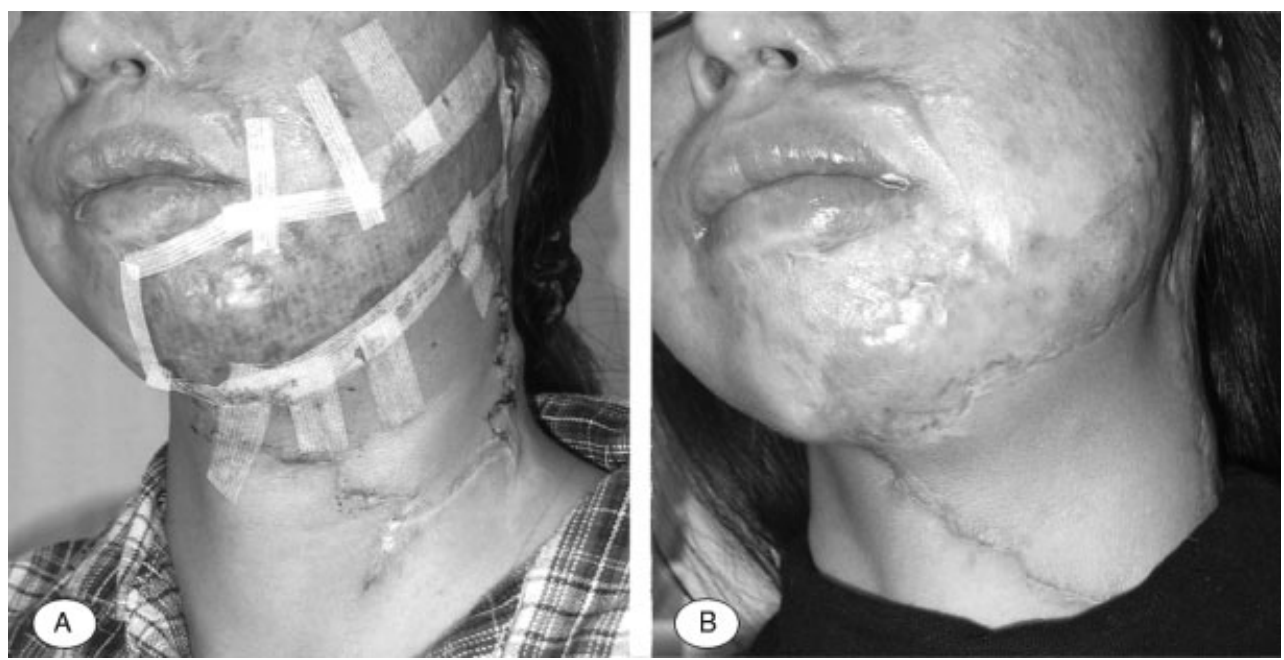

Figure 13 This patient was also the victim of an acid assault and had deep left face and neck burns. The neck scar has been excised, and a thinned anterolateral thigh flap inset. The mandibular margin and lower cheek have been dermabraded with the Versajet (Smith and Nephew, UK) and a thin sheet graft applied. (A) The contour of the face has been much improved, and (B) the patient can now apply cosmetics to camouflage the scarring. 


\section{Fine Tuning}

Several surgical and medical procedures can further enhance the outcome after facial burns. These address the residual scarring that is responsible for the skin texture and pigmentation problems, with vitiligo at one extreme and hyperpigmentation at the other. Aesthetic facial resurfacing can be achieved by dermabrading the bed and applying large intact sheets of skin as splitthickness graft. Such procedures are not to be taken lightly, as they require not only meticulous operative technique but also extremely careful postoperative management. When successful, however, aesthetic facial resurfacing can give rise to excellent results, both in terms of texture and color (Fig. 13).

Areas of vitiligo can be of major psychological concern to patients, and surgical treatments are available. The principal need is to be able to introduce viable melanocytes into the nonpigmented area. This can be achieved by dermabrading the area of vitiligo and seeding it with mixtures of keratinocytes and melanocytes.

Hyperpigmentation can be an equally significant cause of psychological distress. Pigment reduction has been achieved by using intense pulsed light in controlled conditions. $^{57}$

\section{CONCLUSION}

The prevention of complications after burns to the head and neck revolves around protecting vital function in the acute stage and promoting rapid healing. In the reconstructive phase, form and function have to be addressed. The face plays a major role in defining the identity of an individual, and the surgeon must do everything possible to protect that identity despite the presence of scarring. As such, the burns expert must practice truly holistic medicine.

\section{REFERENCES}

1. Kennedy CTC, Burd DAR, Creamer D. Mechanical and thermal injury. In: Champion RH, Burton JL, Burns DA, Breathnach SM, eds. Textbook of Dermatology. 8th ed. Oxford, UK: Blackwell Science; 2004:1-28

2. Burd A. Burn dressings. In: Wnek GE, Bowlin GL, eds. Encyclopedia of Biomaterials and Biomedical Engineering. New York, NY: Marcel Dekker; 2004

3. Burd A, Chiu T. Allogenic skin in the treatment of burns. Clin Dermatol 2005;23:376-387

4. Sheridan R. Acute management of acute facial burns in children. In: Grisolia GA, Corsi A, Landi L, eds. Current Concepts in Pediatric Burn Care. Naples, Italy: Giuseppe de Nicola Editore; 1999:7-17

5. Burd A, Zeng A. Changing perspectives in paediatric burns care. Hong Kong J Paediatr 2003;8:272-282

6. Klein MB, Engrav LH, Holmes JH, et al. Management of facial burns with a collagen/glycosaminoglycan skin sub- stitute-prospective experience with 12 consecutive patients with large, deep facial burns. Burns 2005;31:257-261

7. Lille ST, Engrav LH, Caps MT, Orcutt JC, Mann R. Fullthickness grafting of acute eyelid burns should not be considered taboo. Plast Reconstr Surg 1999;104:637-645

8. Thai KN, Billmire DA, Yakuboff KP. Total eyelid reconstruction with free dorsalis pedis flap after deep facial burn. Plast Reconstr Surg 1999;104:1048-1051

9. Watanabe T, Furuta S, Hataya Y, Yuzuriha S, Otsuka Y. Reconstruction of the eyelids and nose after a burn injury using a radial forearm flap. Burns 1997;23:360-365

10. Fan J. A new technique of scarless expanded forehead flap for reconstructive surgery. Plast Reconstr Surg 2000;106:777-785

11. Hassanpour SE, Davami B. Reconstruction of nose and lips with tubed cervical flap in electrical injury: a case report. Burns 2005;31:510-513

12. Evans DM. Facial reconstruction after a burn injury using two circumferential radial forearm flaps, and a dorsalis pedis flap for the nose. Br J Plast Surg 1995;48:471-476

13. El-Khatib HA, Al-Basti HB, Al-Ghoul A, Al-Gaber H, AlHetmi T. Subtotal reconstruction of the burned auricle. Burns 2005;31:230-235

14. Bhandari PS. Total ear reconstruction in postburn deformity. Clin Plast Surg 2002;29:213-220, vi

15. Akin S. Burned ear reconstruction using a prefabricated free radial forearm flap. J Reconstr Microsurg 2001;17:233-236

16. Takushima A, Harii K, Asato H. Expanded latissimus dorsi free flap for the treatment of extensive post-burn neck contracture. J Reconstr Microsurg 2002;18:373-377

17. Prakash PJ, Gupta AK. The subscapular approach in head and neck reconstruction with the pedicled latissimus dorsi myocutaneous flap. Br J Plast Surg 2001;54:680-683

18. Yang JY, Tsai FC, Chana JS, Chuang SS, Chang SY, Huang WC. Use of free thin anterolateral thigh flaps combined with cervicoplasty for reconstruction of postburn anterior cervical contractures. Plast Reconstr Surg 2002;110:39-46

19. Chin T, Ogawa R, Murakami M, Hyakusoku H. An anatomical study and clinical cases of 'super-thin flaps' with transverse cervical perforator. Br J Plast Surg 2005;58: 550-555

20. Di Benedetto G, Aquinati A, Pierangeli M, Scalise A, Bertani A. From the "charretera" to the supraclavicular fascial island flap: revisitation and further evolution of a controversial flap. Plast Reconstr Surg 2005;115:70-76

21. Lopez CE, Ferro A. Primary reconstruction of anterior neck burns with free flaps. Br J Plast Surg 2005;58:102-105

22. Das-Gupta R, Bang C. Anterolateral thigh perforator flap from previously burned skin for secondary reconstruction of neck with post burn sequelae, new limits explored. Plast Reconstr Surg 2006;59:628-630

23. Tsai FC, Yang JY, Mardini S, Chuang SS, Wei FC. Free split-cutaneous perforator flaps procured using a threedimensional harvest technique for the reconstruction of postburn contracture defects. Plast Reconstr Surg 2004;113: 185-193; discussion 194-195

24. Lin JY, Tsai FC, Yang JY, Chuang SS. Double free flaps for reconstruction of postburn anterior cervical contractures-use of perforator flaps from the lateral circumflex femoral system. Burns 2003;29:622-625

25. Ninkovic M, Moser-Rumer A, Ninkovic M, Spanio S, Rainer C, Gurunluoglu R. Anterior neck reconstruction with pre-expanded free groin and scapular flaps. Plast Reconstr Surg 2004;113:61-68 
26. Tsai FC. A new method: perforator-based tissue expansion for a preexpanded free cutaneous perforator flap. Burns 2003;29:845-848

27. Motamed S, Kalantar Hormozi AJ, Marzban S. Expanded occipito-cervico-pectoral flap for reconstruction of burned cervical contracture. Burns 2003;29:842-844

28. Burd A, Pang PC, Ying SY, Ayyappan T. Microsurgical reconstruction in children's burns. J Plast Reconstr Aesthet Surg 2006;59:679-692

29. Hunt JA, Moisidis E, Haertsch P. Initial experience of Integra in the treatment of post-burn anterior cervical neck contracture. Br J Plast Surg 2000;53:652-658

30. Chen TM, Wang HJ, Chou TD. Correction of retrusive chin in the reconstruction of face and neck burns using sliding genioplasty. Burns 2005;31:918-920

31. Onah II. A classification system for postburn mentosternal contractures. Arch Surg 2005;140:671-675

32. Tolleth H. Parameters of Caucasian attractiveness. In: Matory WE, ed. Ethnic Considerations in Facial Aesthetic Surgery. New York, NY: Lippincott-Raven; 1998:39-60

33. Bauer BS, Vicari FA, Richard ME, Schwed R. Expanded full-thickness skin grafts in children: case selection, planning, and management. Plast Reconstr Surg 1993;92: 59-69

34. Neale HW, Kurtzman LC, Goh KB, Billmire DA, Yakuboff KP, Warden G. Tissue expanders in the lower face and anterior neck in pediatric burn patients: limitations and pitfalls. Plast Reconstr Surg 1993;91:624-631

35. Hudson DA, Quarmby C, Ndobe E. A suture suspension technique to prevent ectropion after flap transposition from the neck to the face. Plast Reconstr Surg 2001;108: 1692-1695

36. Pallua N, von Heimburg D. Pre-expanded ultra-thin supraclavicular flaps for (full-) face reconstruction with reduced donor-site morbidity and without the need for microsurgery. Plast Reconstr Surg 2005;115:1837-1844; discussion 1845-1847

37. Pribaz JJ, Maitz PK, Fine NA. Flap prefabrication using the "vascular crane" principle: an experimental study and clinical application. Br J Plast Surg 1994;47:250-256

38. Khouri RK, Ozbek MR, Hruza GJ, Young VL. Facial reconstruction with prefabricated induced expanded (PIE) supraclavicular skin flaps. Plast Reconstr Surg 1995;95:10071015; discussion 1016-1017

39. Jia C, Chen B, Su Y. Pre-fabricated lined axial flaps for reconstruction of extensive post-burn facial and forehead fullthickness composite defects. Burns 2002;28:688-690

40. Ninkovic M, Hubli E, Anderl H. Facial reconstruction using a retroauricular-temporal free flap. Plast Reconstr Surg 1998; 102:1147-1150
41. Angrigiani C, Grilli D, Karanas YL, Longaker MT, Sharma S. The dorsal scapular island flap: an alternative for head, neck, and chest reconstruction. Plast Reconstr Surg 2003; 111:67-78

42. McCauley RL. Correction of burn alopecia. In: Herndon DN, ed. Total Burn Care. Philadelphia, PA: WB Saunders; 1996:449-502

43. Hudson DA, Grob M. Optimising results with tissue expansion: 10 simple rules for successful tissue expander insertion. Burns 2005;31:1-4

44. Rivera R, LoGiudice J, Gosain AK. Tissue expansion in pediatric patients. Clin Plast Surg 2005;32:35-44, viii

45. Kuckelkorn R, Schrage N, Redbrake C, Kottek A, Reim M. Autologous transplantation of nasal mucosa after severe chemical and thermal eye burns. Acta Ophthalmol Scand 1996;74:442-448

46. Jiaqi C, Zheng W, Jianjun G. Eyelid reconstruction with acellular human dermal allograft after chemical and thermal burns. Burns 2006;32:208-211

47. Nagasao T, Nakajima T, Shimazaki J, Akabane N, Tsubota K. Preliminary repair of eyelids for the treatment of opaque corneas caused by burns. Scand J Plast Reconstr Surg Hand Surg 2005;39:227-233

48. Achauer BM, Adair SR. Acute and reconstructive management of the burned eyelid. Clin Plast Surg 2000;27:87-96, vi

49. Achauer BM. Lip and mouth reconstruction. In: Burn ReconstructionNew York, NY: Thieme Medical Publishers; 1991:64-78

50. Hashem FK, Al Khayal Z. Oral burn contractures in children. Ann Plast Surg 2003;51:468-471

51. Daya M, Mahomva O, Madaree A. Multistaged reconstruction of the oral commissures and upper and lower lip with an island submental flap and a nasolabial flap. Plast Reconstr Surg 2001;108:968-971

52. Rudkin GH, Carlsen BT, Miller TA. Nasolabial flap reconstruction of large defects of the lower lip. Plast Reconstr Surg 2003;111:810-817

53. Hafezi F, Naghibzadeh B, Nouhi A. Facial reconstruction using the visor scalp flap. Burns 2002;28:679-683

54. Demir Z, Kurtay A, Sahin U, Velidedeoğlu H, Celebioğlu S. Hair-bearing submental artery island flap for reconstruction of mustache and beard. Plast Reconstr Surg 2003;112:423-429

55. Conley J, Norris JE. Reconstruction of half of the face. Arch Otolaryngol 1985;111:142-145

56. Angrigiani C, Grilli D. Total face reconstruction with one free flap. Plast Reconstr Surg 1997;99:1566-1575

57. Ho WS, Chan HH, Ying SY, Chan PC, Burd A, King WW. Prospective study on the treatment of postburn hyperpigmentation by intense pulsed light. Lasers Surg Med 2003; $32: 42-45$ 